\title{
Evaluation of Tensile Strength of a Eucalyptus grandis and Eucalyptus urophyla Hybrid in Wood Beams Bonded Together by Means of Finger Joints and Polyurethane-Based Glue
}

\author{
Marcos Cesar de Moraes Pereira ${ }^{*}$, Carlito Calil Neto ${ }^{a}$, Felipe Hideyoshi Icimoto ${ }^{a}$, Carlito Calil Junior ${ }^{a}$ \\ a Departamento de Engenharia de Materiais e Laboratório de Madeiras e de Estruturas de Madeira \\ - LaMEM, Escola de Engenharia de São Carlos - EESC, Universidade de São Paulo - USP, Av. \\ Trabalhador Sancarlense, 400, 13.566-590, São Carlos, SP, Brazil
}

Received: January 27, 2016; Revised: August 04, 2016; Accepted: August 20, 2016

\begin{abstract}
Created in the 1940s, the splice finger-joint type for wood has now been more used to compose structural materials wood base as Glued Laminated Timber (Glulam) and Cross Laminated Timber (CLT). The main advantage of this amendment is to provide a simple and economical way to join timber parts on segments. This study evaluated by means of tensile tests the capacity of this type of joint (structural dimension of $21 \mathrm{~mm}$ ) to bond together Lyptus ${ }^{\circledR}$ wood beams (a Eucalyptus grandis and Eucalyptus urophyla hybrid) using Jowat polyurethane glue (Model 680.20) as compared to similar seamless beams. The results indicate that the seamless beams are $47.72 \%$ more resistant to traction (in characteristic values) than those with finger joints. However, to form structural elements where there is redundancy overlapping parts, such as Glulam and CLT, the values obtained can be considered satisfactory. Also noted is that denser samples have better traction results due to better bonding of the densest parts. The use of finger-joint and polyurethane adhesive o bond hybrid eucalyptus, although more brittle than wood without seams, enable the use of shorter wood sections for the composition of major structural elements, optimizing better forest material.
\end{abstract}

Keywords: Tensile test, Finger joints, Lyptus ${ }^{\circledR}$, Eucalyptus grandis, Eucalyptus urophyla

\section{Introduction}

The invention of finger joints for wooden structures, known as finger joints, is commonly attributed to Karl Egner and Jagfeld from Otto Graf Stuttgart Technischer Hoschuele prior to the Second World War. This technique was employed by German forces to repair structural damages resulting from bombing from 1939 to $1945^{1}$. A 1947 study conducted by these authors included reviews of finger joints in wooden bridges built in 1937. However, despite this being the first known reference to structural use of finger joints, German and American automotive industry had already employed some kind of toothed joint in the manufacture of wooden steering wheels and wooden parts of car wheels in the $1920 \mathrm{~s}^{2}$.

Finger joints and glue can be used to bond together two pieces of wood lengthwise on the same plane without resorting to hardware or wooden dowels so as to obtain longer pieces of wood, thereby increasing the use of shorter pieces. It also allows the removal of large nodes from wood pieces and putting them back together afterwards. The advantage of finger joints over other types of joints such as beveled or top joints (Figure 1) is that top joints yield very low mechanical strength, i.e., they do not transmit efforts to the adjacent piece effectively whereas beveled joints, though yielding good strength, demand a lot of wood to be manufactured, since bevels must have a 1:10 slope ${ }^{3}$. Thus

* e-mail: marcoscesar@sc.usp.br finger joints provide an economical approach for joining pieces segments longitudinally ${ }^{4}$.

The use of wood pieces bonded together lengthwise is particularly suitable for manufacturing glued laminated timber (Glulam) beams and CLT (Cross Laminated Timber) boards, in which wood lamellas are glued together to obtain a wooden beam, arc or boards with special dimensions. Section 5.7.4 of the draft revision (2011) of Brazilian Standards for Wooden Structures - NBR $7190^{5}$ addresses the use of Glulam and indicates the required dimensions for finger joints. In order to be considered structural, finger joints have to have the following dimensions:

The geometric parameters cited in Table 1 are presented in Figure 2.

For finger joints to yield the necessary strength to withstand tensile loads, it is necessary to use glues whose structural features and properties are compatible with the environmental conditions to which the wooden structure will be subjected during its service life. There are several structural wood glues, the most common ones being those based on phenol resorcinol, melamine formaldehyde, and polyurethane. Gluing parameters, e.g., quantity, pressure, and pressing time, vary according to manufacturers. In the absence of manufacturer parameters, NBR 7190 recommends the pressure for finger joints to be at least $0.7 \mathrm{MPa}$ for wood with density below $0.5 \mathrm{~g} / \mathrm{cm}^{3}$ and $1.2 \mathrm{MPa}$ for wood with density above $0.5 \mathrm{~g} / \mathrm{cm}^{3}$. Similarly, in the absence of manufacturer recommendations, 


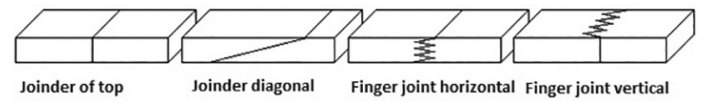

Figure 1: Types of joints ${ }^{1}$.

Table 1: Geometric specifications for teeth recommended by NBR 7190.

\begin{tabular}{lcc}
\hline Parameter & Profile 1 & Profile 2 \\
\hline $\mathrm{L}_{\mathrm{d}}-$ length of tooth $(\mathrm{mm})$ & 28 & 21 \\
$\mathrm{t}_{\mathrm{d}}-$ width of tooth base $(\mathrm{mm})$ & 7 & 7 \\
$\mathrm{~b}_{\mathrm{d}}-$ width of tooth end $(\mathrm{mm})$ & 1 & 1 \\
$\mathrm{~T}_{\mathrm{g} \mathrm{g}}-$ (slope) & $1: 10$ & $1: 9$ \\
\hline
\end{tabular}
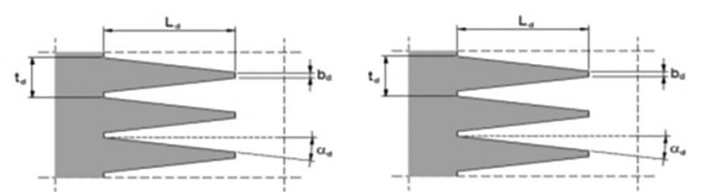

Figure 2: Geometric parameters for finger joints of the fingerjoint type ${ }^{5}$.

the pressing time should be six hours at about 20 degrees Celsius and relative humidity around $65 \%{ }^{5}$.

Densest timbers tend to have a higher tensile strength in the notched amendment compared the less dense woods ${ }^{6}$. this behavior is shown in published results, especially among dicotyledonous woods that are denser and conifers that are less dense. This study evaluated the amendment finger-joint type of wood Lyptus, a hybrid of two species of eucalyptus (Eucalyptus grandis and Eucalyptus urophyla hybrid species). This timber has an average density $750 \mathrm{~kg}$ $/ \mathrm{m}^{3}$, and can be considered a medium density wood. The samples analyzed were structural size, and were divided into two groups, one group with finger-joint amendments and other without amendments, the same part, ie, the tested samples had 2 meters long, and the original pieces that gave rise to samples with and without finger had 4 meters long. The samples were manufactured and supplied by Ita Construtora, a Brazilian company that designs, manufactures and assembles Glulam beams. The polyurethane-based glue in question is manufactured by Jowat (Model 680.20) ${ }^{7}$.

\section{Materials and methods}

In order to prepare the test samples, specific cutters were employed to carve finger joints with final tooth length (L) of $21 \mathrm{~mm}$. Soon afterwards, Jowat glue (680.20 Model) was applied to them (weight as recommended by the manufacturer). Then, they were pressed at a load of $0.7 \mathrm{MPa}$ using a specific press.

The tensile tests were performed on a Model 422 Metriguard machine, which measured the tensile strength and rupture mode of samples with and without finger joints, as recommended in item 13.2 do EN 408:2010 Timber structures: Structural timber and glued laminated timber - Determination of some physical and mechanical properties $^{8}$.

According to Appendix B (Determination of properties of wood for design of structures) of NBR 7190 — Brazilian Standards for Wooden Structures ${ }^{5}$, which defines testing methods for structural wooden elements, the tensile strength parallel to the fibers $\left(f_{w t, 0}\right.$ or $\left.f_{t 0}\right)$ is given by the maximum tensile stress that can act on an elongated sample whose central portion has a uniform cross section area $A$, length equal to or above $8 \sqrt{ } A$, ends stronger than central portion, and concordances that ensure rupture at the central portion, as follows:

$$
f_{t 0}=\frac{F_{t 0}}{A}
$$

Where $F_{t 0}$ is the maximum tractive force applied to the sample during the test, expressed in Newton (N), $A$ is the cross section area, expressed in $\mathrm{m}^{2}$, and $f_{t 0}$ is the tensile strength parallel to the fibers, expressed in $\mathrm{MPa}$.

The European Standard EN $408{ }^{8}$ presents in item 13.1 the test setup to be done, as Figure 3 shows.

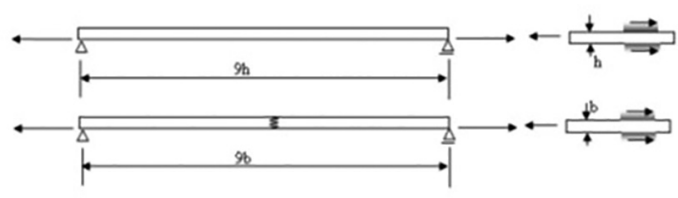

Figure 3: In tensile testing scheme for timing amendments ${ }^{8}$.

The characteristic tensile stress values of the samples are estimated according to Item B.3 of Appendix B of NBR $7190^{5}$, which describes testing methods for determination of properties of wood for structural design, in which:

$$
X_{w k}=\left(2 \frac{X_{1}+X_{2}+\ldots+X_{\frac{n}{2}-1}}{\frac{n}{2}-1}-X_{\frac{n}{2}}\right) \cdot 1.1
$$

Where $X_{w k}$ is the generic characteristic strength, in MPa; $n$ is the number of samples; $X_{1}$ is the strength of Sample 1, in $\mathrm{MPa} ; X_{2}$ is the strength of Sample 2 , in $\mathrm{MPa}$; and $X_{n}$ is the strength of the $\mathrm{n}^{\text {th }}$ sample in $\mathrm{MPa}$.

The standard in question recommends the characterization of at least 12 samples, whose values should be placed in ascending order $X_{1}<X_{2}<\ldots<X_{n}$, disregarding the highest value if the number of samples is odd and discounting $X_{w k}$ values lower than $X_{1}$ or lower than 0.7 of mean value $\left(\mathrm{X}_{\mathrm{m}}\right)$.

Table 2 shows the dimensions of each sample. 
Table 2: Dimensions of specimens with finger joint.

\begin{tabular}{lcccc}
\hline Specimen & \multicolumn{2}{c}{ Dimensions $(\mathrm{cm})$} & Weight $(\mathrm{kg})$ & Length $(\mathrm{cm})$ \\
\hline 1 & 88.88 & 32.85 & 4.55 & 202.9 \\
2 & 88.67 & 32.50 & 4.60 & 202.6 \\
3 & 91.37 & 32.48 & 3.80 & 202.8 \\
4 & 90.19 & 32.74 & 4.45 & 202.2 \\
5 & 91.26 & 33.09 & 2.80 & 202.7 \\
6 & 91.45 & 32.47 & 3.30 & 203.0 \\
7 & 91.45 & 32.25 & 3.60 & 202.2 \\
8 & 91.26 & 32.77 & 2.75 & 199.3 \\
9 & 89.64 & 32.63 & 4.40 & 204.0 \\
11 & 89.30 & 32.21 & 5.00 & 202.9 \\
12 & 93.19 & 32.70 & 4.15 & 203.0 \\
\end{tabular}

\section{Results and discussion}

The Table 3 shows the test results for beams with finger joints, and shows mode of rupture, showing the type of rupture (wood or adhesive) and the amount of each in a percentage relative to the cross sectional area of the test region, as recommended by the point ' $n$ ' the item 7.1.3.4 of DIN EN $385^{9}$.

Table 4 shows dimensions and results for samples with no finger joints.

The characteristic tensile strength value found for sample with finger joints was $24.21 \mathrm{MPa}$, and this value is greater than the value of samples that had the lowest amount of tension that was $23.63 \mathrm{MPa}$ and higher than the mean value $\left(X_{m}=19.10 \mathrm{MPa}\right)$, thereby meeting the requirements in Item B of NBR $7190^{5}$.

The characteristic tensile strength value found for samples without finger joints was $40.27 \mathrm{MPa}$, and this value is greater than the value of samples that had the lowest amount of tension that was $22.06 \mathrm{MPa}$, but lower than the mean value $\left(X_{m}=50.73 \mathrm{MPa}\right)$. Thus, in order to meet the aforementioned standard requirements, the characteristic value should now be the mean value $(50.73 \mathrm{MPa})$. The Table 5 shows the characteristic values obtained in the tests, Figures 4 and 5 examples of ruptures in samples with fingers joint seams. The statistical values of the tests are shown in Figures 6, 7, 8 and 9 as well as the comparative tensile strength values of samples with and without finger joints shown in Figure 10.

The Table 6 shows the variability between samples with and without finger joints (\%), Figure 11 shown comparative density to tensile strength for samples with finger joints and the Figure 12 shown comparative density to tensile strength for samples without finger joints.

The analysis of the results indicates that of all the samples under investigation, those without finger joints yielded the highest tensile test results. This is certainly due to the fact that their fibers have not been broken up, unlike those with finger joints, which do not transmit tensile loads as effectively in spite of their glued surface. Any denser wood species as denser samples, have a value of tensile strength greater with finger-joint splice as shown in Figure 11 , when compared to the use of less dense species or

Table 3: Tensile test results for specimens with finger joints.

\begin{tabular}{lccccc}
\hline SP & Maximum load (KN) & Evaluation of Rupture & Mode of Rupture & Tensile strength & Density \\
\hline 1 & 87 & $100 \%$ & Glue & 29.80 & 768.1 \\
2 & 87 & $100 \%$ & Glue & 30.19 & 787.9 \\
3 & 83 & $36 \%$ & Wood & 27.97 & 631.4 \\
4 & 74 & $43 \%$ & Wood & 25.06 & 745.3 \\
5 & 71 & $7 \%$ & Wood & 23.51 & 457.4 \\
6 & 75 & $100 \%$ & Glue & 25.26 & 547.5 \\
7 & 78 & $100 \%$ & Glue & 26.45 & 603.7 \\
8 & 62 & $36 \%$ & Wood & 20.73 & 461.4 \\
9 & 93 & $100 \%$ & Glue & 31.80 & 737.4 \\
10 & 99 & $21 \%$ & Wood & 34.42 & 856.7 \\
11 & 72 & $50 \%$ & Wood/Glue & 23.63 & 670.9 \\
12 & 84 & $100 \%$ & Glue & 28.67 & 585.9 \\
\hline
\end{tabular}


Table 4: Tensile test results for specimens without finger joints.

\begin{tabular}{lccccccc}
\hline SP & \multicolumn{2}{c}{ Dimensions $(\mathrm{cm})$} & Weight $(\mathrm{Kg})$ & Length $(\mathrm{cm})$ & Maximum load $(\mathrm{KN})$ & $\begin{array}{c}\text { Tensile strength } \\
(\mathrm{MPa})\end{array}$ & Density $\left(\mathrm{Kg} / \mathrm{m}^{3}\right)$ \\
\hline 1 & 86.39 & 32.89 & 4.4 & 200.0 & 246 & 86.58 & 774.3 \\
2 & 86.27 & 32.09 & 4.4 & 200.2 & 170 & 61.41 & 793.9 \\
3 & 86.51 & 32.57 & 3.7 & 199.9 & 143 & 50.75 & 656.9 \\
4 & 86.33 & 32.38 & 4.35 & 200.2 & 289 & 103.39 & 777.3 \\
5 & 86.69 & 32.49 & 2.85 & 200.2 & 206 & 73.14 & 505.4 \\
6 & 84.84 & 32.43 & 3.15 & 200.2 & 230 & 83.59 & 58.41 \\
7 & 86.79 & 32.45 & 3.5 & 200.0 & 249 & 22.06 & 621.4 \\
8 & 86.73 & 32.4 & 2.85 & 200.1 & 62 & 63.82 & 506.9 \\
9 & 85.62 & 32.39 & 4.4 & 200.0 & 177 & 77.16 & 793.3 \\
10 & 86.53 & 32.35 & 4.9 & 200.2 & 216 & 71.02 & 874.4 \\
11 & 86.8 & 31.31 & 4.05 & 200.0 & 193 & 88.43 & 745.1 \\
12 & 86.19 & 32.54 & 3.3 & 200.0 & 248 & 588.3 \\
\hline
\end{tabular}

Table 5: Comparison between characteristic tensile test values.

\begin{tabular}{lll}
\hline Characteristic value with finger joint (MPa) & Characteristic value without finger joint (MPa) & Variability (\%) \\
\hline 24.21 & 50.73 & 47.72 \\
\hline
\end{tabular}

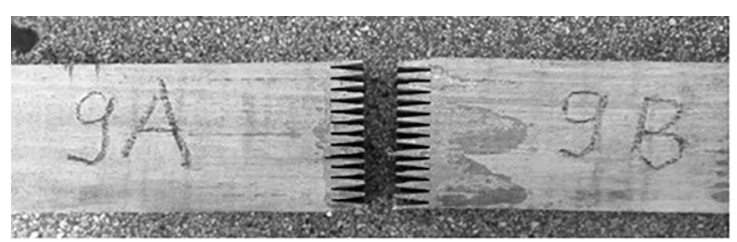

Figure 4: Specimen with finger joint before gluing.

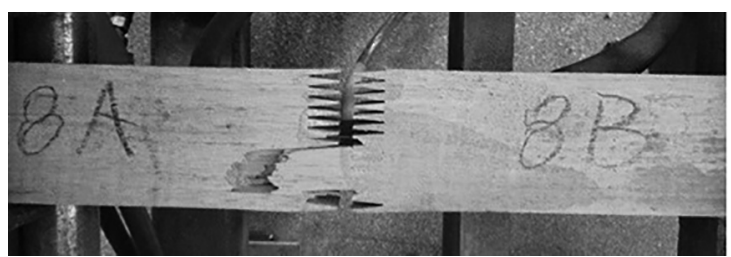

Figure 5: Specimen with finger joint right after rupture $(50 \%$ in the wood and $50 \%$ in the glue).

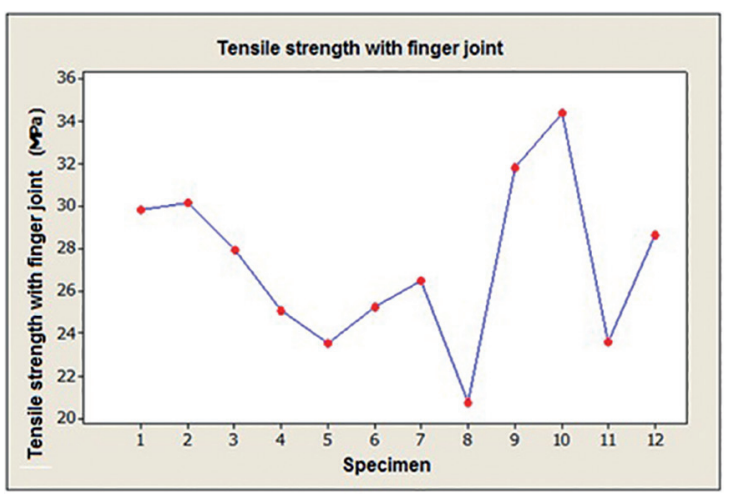

Figure 6: Chart showing tensile strength values for sample with finger joints.

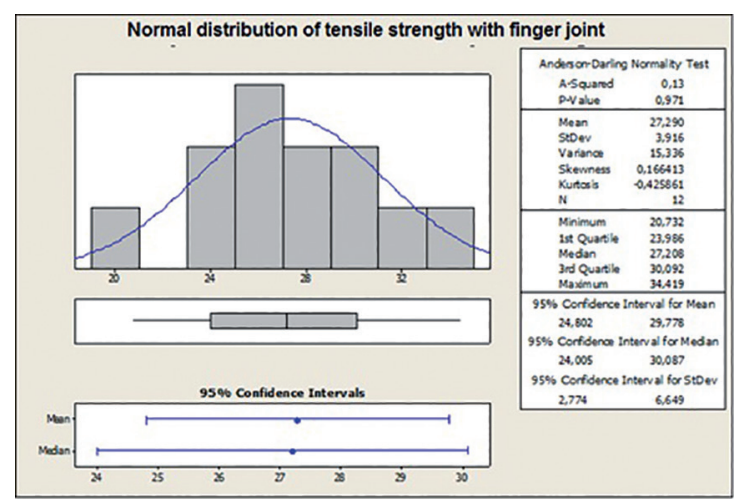

Figure 7: Histogram showing tensile strength values for samples with finger joints.

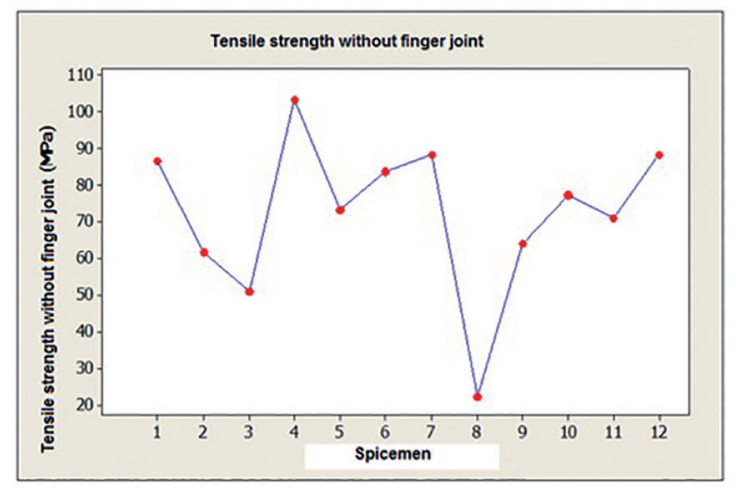

Figure 8: Chart showing tensile strength values for samples without finger joints. 


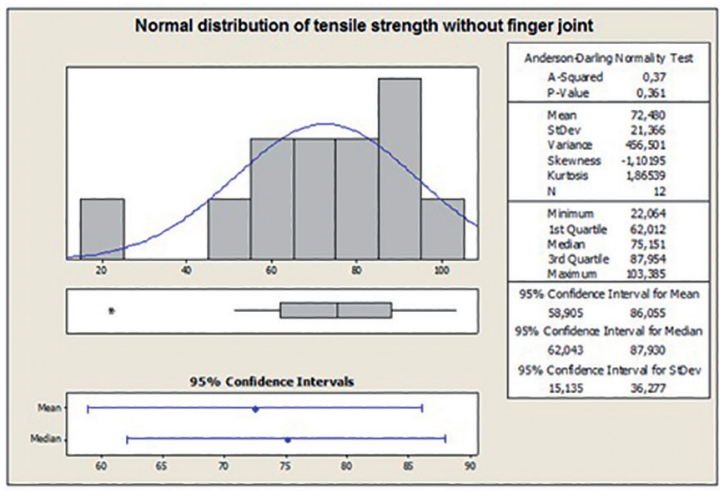

Figure 9: Histogram showing tensile strength values for samples without finger joints.

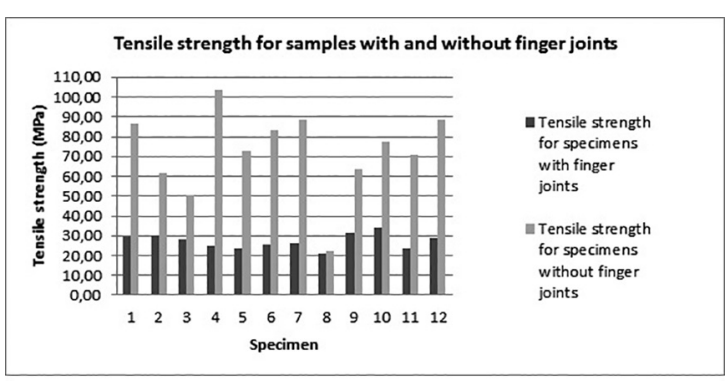

Figure 10: Chart comparing tensile strength values of samples with and without finger joints.

Table 6: Variability of tensile values between specimens with and without finger joints.

\begin{tabular}{lc}
\hline Specimen & $\begin{array}{c}\text { Variability between specimens with and without } \\
\text { finger joints (\%) }\end{array}$ \\
\hline 1 & $191 \%$ \\
2 & $103 \%$ \\
3 & $81 \%$ \\
4 & $313 \%$ \\
5 & $211 \%$ \\
6 & $231 \%$ \\
7 & $234 \%$ \\
8 & $-*$ \\
9 & $101 \%$ \\
10 & $124 \%$ \\
11 & $201 \%$ \\
12 & $208 \%$ \\
Mean & $182 \%$ \\
\hline
\end{tabular}

*result for Specimen 8 may be disregarded as it falls far from the tendency curve.

strains. This behavior is found in the literature. The Kuring species (Dipterocarpus sp.) which has density $780 \mathrm{~kg} / \mathrm{m}^{3}$, together with polyurethane adhesive (PU) for finger-joint type splices obtained average results of $63.76 \mathrm{MPa}$ tensile strength, while less dense coniferous species, Southern Pine and Douglas Fir obtained mean values of 55.99 MPa and $54.64 \mathrm{MPa}$, respectively ${ }^{6}$.

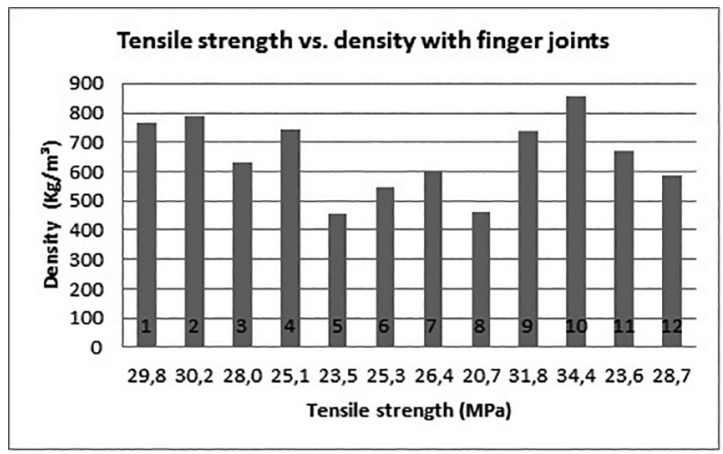

Figure 11: Chart comparing density to tensile strength for samples with finger joints.

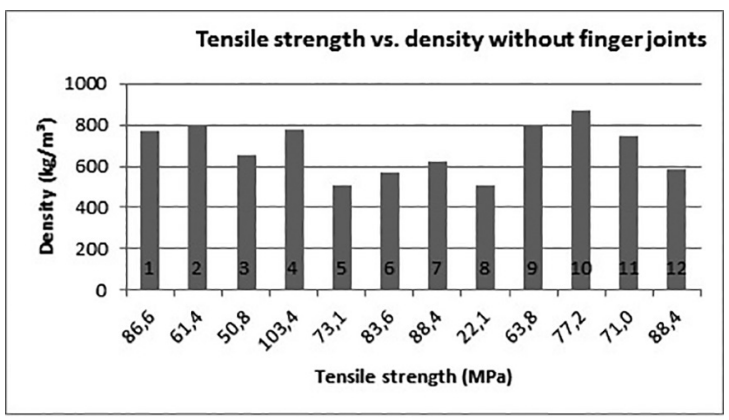

Figure 12: Chart comparing density to tensile strength for samples without finger joints.

In tests with wood species Manilkara sp. (Maçaranduba), joining two pieces through finger-joint using polyurethane adhesive (PU) was obtained average values tensile strength of $73.78 \%$ lower for the united samples compared to samples without emendas ${ }^{10}$. Also for testing the adhesive base of resorcinol-phenol joining pieces of wood species Eucalyptus grandis the results obtained by the authors in the tensile strength test were twice as high for wood seamless compared to wood with finger-joint ${ }^{1}$.

The mean tensile strength variability of seamless samples was $167 \%$ higher than that of samples with finger joints. Sample 8 was the only sample yielding similar values in both situations; it obtained a much lower tensile strength value than the mean value for the test on samples without joints. However, this discrepant behavior does not represent any statistically relevant tendency.

The characteristic values shown in Table 4 indicate lower variability $(47.72 \%)$, this statistic estimation being recommended by the Brazilian standard for wooden structures, i.e., NBR $7190^{5}$ for characterizing consignments of wood and new wood species.

As the samples with and without joints derive from the same wood samples, the comparison between their densities and tensile strengths indicates similar behavior, as shown in Figures 11 and 12.

The glue-wood behavior was shown to be inadequate. The data in Table 3 indicate that $50 \%$ of the samples in question 
broke up along the gluing line, i.e. the glue was not capable of transmitting the efforts efficiently and ruptured before the wood fibers did in half of the cases under investigation. As to those samples whose wood fibers ruptured, was also breaking the adhesive. Furthermore, the glue was weaker than the wood in all cases, as shown in Figure 5.

\section{Conclusion}

It is possible to conclude that samples made of Lyptus ${ }^{\circledR}$ wood (a Eucalyptus grandis and Eucalyptus urophyla hybrid) bonded together by finger joints of the finger-joint type with $21 \mathrm{~mm}$ teeth in and Jowat polyurethane glue (Model 680.20) yield tensile strength $47.72 \%$ lower than samples made of the same wood without finger joints.

It is also concluded that although the tensile strength is lower spliced into pieces with finger joints, the use of fingerjoint allows the use of short pieces considered for structural use, taking advantage of the best available natural resource and to compose a Glulam or CLT where there is redundancy of more rigid elements. In this case, should be tested in the laboratory with the requirements for each product, for example, minimum distances between amendments on the same slide stipulated by paragraph 5.7.4.7.1 of the draft revision of Brazilian Norm NBR 7190, are respected. In addition, it is recommended that different combinations of glue, wood species, and chemical treatment be tested to verify the quality of the bonding finger joints in structural beams.

The results confirm the literature and show that the density of the piece influences on tensile strength and can be concluded that this occurs due to the longitudinal direction of the joining direction where the fibers are disposed at the top of the pieces bonded, where denser woods have more fibers per unit area, but the influence of other natural or anatomical characteristics of the wood can interfere, in order it's not possible to say that this relationship is a rule for all wood species.

\section{References}

1. Macedo AN. Emendas Dentadas em Madeira Laminada Colada (MLC): Avaliação de Método de Ensaio. [Dissertation]. São Carlos: Universidade de São Paulo; 1996.

2. Jokerst RW. Finger-Jointed Wood Products. Madison: US Department of Agriculture, Forest Service, Forest Products Laboratory; 1981.

3. Macedo AN, Calil Junior C. Estudo de emendas dentadas em madeira laminada colada (MLC): avaliação de método de ensaio - NBR 7190/1997. Cadernos de Engenharia de Estruturas. 1999;3:1-23

4. Brandner R. Production and Technology of Cross Laminated Timber (CLT): A state-of-the-art Report. In: Focus Solid Timber Solution - European Conference on Cross Laminated Timber (CLT); 2013 May 21-22; Graz, Austria. p. 3-36.

5. Associação Brasileira de Normas Técnicas. Projetos de estruturas de madeira. Rio de Janeiro: Associação Brasileira de Normas Técnicas; 1997. p. 1-75.

6. Vrazel M, Sellers T Jr. The effects of species, adhesive type, and cure temperature on the strength and durability of a structural finger-joint. Forest Products Journal. 2004;54(3):66-75.

7. JOWAT. Jowat with certificate: 1-component PUR adhesives. 2010;49:9-10.

8. Beuth Standards Solutions. DIN EN 408 - Structural timber and glued laminated timber - Determination of some physical and mechanical properties. Berlin: Beuth Standards Solutions; 2004. p. 35 .

9. Engineering 360. DIN EN 385: Finger-jointed structural timber. New York: Engineering 360; 2002. p. 16.

10. Molina JC, Calil Neto C, Christoforo AL. Tensile strength of finger joints made of Manilkara huberi wood for use in glued laminated timber. Ambiente Construido. 2016;16(1):221-227. 